\title{
Making Databases Relevant in the Accounting Information Systems Course: Exercises for the Classroom
}

\author{
Janette Moody \\ The Citadel, Charleston, SC, USA
}

\author{
Janette.Moody@Citadel.edu
}

\begin{abstract}
The pivotal role played by computers in acquiring, storing, and processing financial information requires that accountants, and therefore accounting students, have a thorough understanding of the underlying principles of data composition and data structures. In addition, in order to facilitate the deep learning that will sustain these students past the point-and-click mechanics of the software $d u$ jour, it is important that a pedagogical strategy such as problem-based learning be used in the classroom, especially during the early learning phases of database courses. This presentation will provide some specific exa mples of classroom exercises designed to incorporate the student's current knowledge of everyday business situations with higher order concepts of data models and their impact on managerial information. The presentation will first discuss the current state of Accounting Information Systems curricular, the concepts of problem-based learning, and examples of clas sroom exercises to teach database concepts to accounting students.
\end{abstract}

\section{Introduction}

Accounting information systems of the past focused on the recording, summarizing and validating of data about business financial transactions. These functions were performed for the various groups within the organization that were concerned about the respective decisions associated with financial accounting, managerial accounting, and tax compliance issues (Hollander, Denna, \& Cherrington, 1996). The need to integrate these often diverse systems led to the accountant's appreciation of shared databases that provide a cohesive picture of the organization's data, eliminating duplications and reducing data conflicts (Moscove, Simkin, \& Bagranoff, 1999). Therefore, one important aspect of the accounting student's learning involves a thorough understanding of database development. This has been recognized by the American Institute of Certified Public Accountants (AICPA) and the Information Systems Audit and Control Association (ISACA), which have prepared guidelines for an accounting information systems (AIS) education. These guidelines include at least one course in database management systems. However, there are only a few AIS programs in universities with AACSB-accounting accreditation (Calderon, Cheh, \& Chatham, 2002), resulting in many schools having to squeeze database deve 1opment concepts into a single course on information technology for accountants. Even for those rare students who have worked with the database features of Excel@, the typical gateway software for accountants, accounting students have traditionally been focused primarily on the challenges of placing

Material published as part of these proceedings, either on-line or in print, is copyrighted by Informing Science. Permission to make digital or paper copy of part or all of these works for personal or classroom use is granted without fee provided that the copies are not made or distributed for profit or commercial advantage AND that copies 1) bear this notice in full and 2) give the full citation on the first page. It is permissible to abstract these works so long as credit is given. To copy in all other cases or to republish or to post on a server or to redistribute to lists requires specific permission from the publisher at Publisher@InformingScience.org business transactions in the proper context according to Generally Accepted Accounting Principles, rather than being concerned with the attributes of the data itself or for that matter, any non-financial data.

The terminology of database deve lopment such as tuples, foreign keys, referential integrity, first normal form, etc. can be confusing if introduced 
before the student understands desired outcomes and benefits of databases. One way to minimize this confusion is to require the student to draw upon his or her current business knowledge. By tying these experiences to the deeper underlying attributes of data, the learning process can be greatly enhanced. The goal is to provide the student with the tools to turn data into information, and information into knowledge that can support and advance the business objectives.

One way to accomplish this is through problem-based learning. The usefulness of problem-based learning has been demonstrated for various Information Systems (IS) topics (Rosenbaum, 2001) and for the education of accounting professionals (Milne, 1999). Problem-based learning (PBL) has been successfully used as an instructional method for many years in the medical profession (Duffy and Cunningham, 1996). Outcome assessments reveal the value of PBL is not so much measured by the results on standardized tests but by its effect on the longer-term retention of the knowledge (Albanese and Mitchell, 1993). PBL is succinctly defined by Wilson and Cole (1996) as a method that "integrates the learning of content and skills, utilizes a collaborative environment, and emphasizes "learning to learn" by placing most of the respons ibility for learning on the learner rathe $r$ than providing a sophisticated pre-designed instructional system" (p. 609). Specifically, PBL "begins with activating prior knowledge to enable students [to] understand the structure of the new information"(Grabinger, 1996, p. 674). Furthermore, in order for learning transfer to occur, "the learning context [must be] similar to the situation in which the learning is to be applied" (Grabinger, 1996, p.674).

Thus the challenge for educators is to create realistic problems (Bradbard, 2001) in a context that draws upon the student's prior knowledge in order to utilize PBL. In light of the research supporting the educational value of PBL, the goal of this paper is to offer such examples. The examples listed below draw upon the student's current superficial knowledge of general business transactions in order to increase the student's awareness of the ubiquity of data, not just financial data, in the organization, its importance as the basis for all business decisions, and the processes necessary to insure its reliability. Although these exercises were designed for accounting students who may only receive one course in information systems, they are applicable for all non-IS majors who require an appreciation of and increased familiarity with database concepts.

\section{Stage 1: Initial Class Exercise}

GOAL: To view a simple business transaction from a variety of perspectives in order to capture data that can be turned into information.

PBL Principle: Activate prior knowledge as foundation for new learning

On the first day of class, students are introduced to the necessity of capturing various pieces of data from a single business transaction. The instructor has created mock-ups of books (fiction, non-fiction, selfhelp, refe rence, etc.) by folding sheets of paper into fourths and writing a title, product code and a price on the "cover". The quantity of books (of various prices and types) created should be approximately three times the number of students in the class. (With enough time and creativity, the books can be made to look like miniatures of their real counterparts.) The books are spread out on a table in the front of the room.

The class is divided in half, with one half of the students being "Buyers" and the other half being "Sellers". The Buyers "shop" by picking up several books and taking them to a Seller. It's the Seller's job to write out a receipt for this transaction that he gives to the Seller who can then sit down. No further instructions are given.

The instructor looks at the receipts and selects an example of very limited data captured and an example of very extensive data captured. These are projected overhead or re-constructed on the blackboard. The points regarding what pieces of data were captured and what pieces should have been captured are dis- 
cussed as students think of other things they could have placed on the receipts. It is common for basic pieces of information such as date, product code, quantity, etc. to be omitted in the first exercise.

The instructor now asks students to remove a real receipt from his or her wallet and examine its contents. Several students share their receipts to see which captured the most and which captured the least. The extensive data captured and printed by most POS systems provide a perfect starting point for discussions regarding how the data will be used as a basis for management decisions. For example, the time of day of the transaction and the cash register number can indicate whether or not a second shift is required. The recurring patterns of certain products being purchased together can suggest new ways of displaying merchandise, and so forth. Accounting students also find this is a good time to discuss the ways the data can assist in auditing certain transactions such as the personnel on duty at the time or the dual signatures required for the return of merchandise for cash. Based on their new awareness of the importance of capturing data at its point of origin, they are ready to understand the concepts behind database systems deve lopment.

\section{Stage 2: Presentation of Database Concepts}

GOAL: To tie the initial exercise to learning database concepts

PBL Principle: Provide learning context similar to one in which it will be applied

Now that the students see the importance of non-financial as well as financial data for management decisions, the class can turn to the concepts behind the basic building blocks of a database. This is covered without the use of a text by building a simple database for the bookstore used in the initial class exercise. The discussion begins about the hierarchy of data as it moves through bit, byte, field, record, file up to a database. The importance of a data dictionary to standardize and define each piece of data is emphasized. Then the concepts of entities and attributes are introduced.

The importance of understanding this company's business rules is introduced. Such questions as "how many customers can be on an invoice?", "should invoices be pre-numbered?", "how many sales reps can be on an invoice?", "do sales reps earn commissions based on their seniority or the product being sold?" help define how the data will be stored and retrieved.

This database will contain five tables: Products, Customers, Sales Reps, Invoices, and Invoice Details. Students discuss what fields should be in each table and why, which leads into the concept of table normalization. The importance of referential integrity, built-in data validation rules, and other important concepts are presented here. For example, the Sales Reps table can include photos and biometrics such as fingerprints. Students begin to realize that anything that can be digitized can be stored. This introduces the topic of how pictures and sounds can be an integral part of a database, moving the students well beyond just financial data types.

The various objects of a database and their role in providing management with data organized into information helps students appreciate the flexibility of a relational database for answering ad hoc requests. By taking notes and participating in the discussions, students have enough information to begin to create a database in Access $2000 ®$ for the bookstore, use queries to extract data in response to ma nagement's questions, and prepare reports with calculations, subtotals, and totals for each customer by invoice. They quickly find out the importance of properly entered data when a report comes up short of the total number of products sold. Tracking down the cause may reveal for example a transposition in entering a product code or customer ID. Discovering the consequences of inaccurate data leads to a discussion of the development of forms and drop down boxes to speed data entry and ensure data accuracy.

The instructor can then ask for management reports that cannot be derived from the database as developed and students learn how they can add fields to tables, and what the consequences are on the other 
objects in the database. Based on their understanding of database concepts and the mechanics of putting them into action, they are now ready to create one on their own from scratch.

\section{Stage 3: Student Created Databases}

GOAL: To provide an independent student learning experience based on Stages 1 and 2.

PBL Principle: Develop "learning to learn" skills by placing responsibility for learning on the learner.

Students are asked to start a small fictitious business and support it with a database. No restrictions are placed on the type of business except that it must have identifiable customers. Since most students have a hobby or some entreprene urial dream, they enjoy the idea of starting a business on paper and fleshing it out with specifics. This written project includes:

- An Executive Summary with an overview of the company's goals and challenges.

- Five tables (Products, Customers, Sales Reps, Invoices, and Invoice Details) with the Customer table having at least 10 fields, each of which must be of importance to the business for developing and solidifying customer relationships.

- A query that links all five tables in order to compute a total for each sale (price x quantity), sales commissions, and grand totals.

- A report that lists all sales, by item, subtotaled by Invoice, then by Customer, and finally as a grand total.

- A paragraph interpreting the report and what actions management might take based on the information.

- A PowerPoint presentation to the class presenting the business.

\section{Stage 4: Applicability in Accounting Software Packages}

GOAL: To use learning from previous Stages to evaluate new software

PBL Principle: Develop "learning to learn" skills by placing responsibility for learning on the learner.

With the speed of technological change being a given, the goal of this class is not just to teach students how to work with one software package. Rather, their work in creating a database will provide them with skills to be utilized in assessing and evaluating new software for its ease of use, built-in controls, and flexibility of outputs. Therefore, students are given a chance to see how some sophisticated software packages work, and can critique them along the lines just noted. As a final part of the class, students are introduced to two accounting software packages: an auditing package called IDEA® and Microsoft's Great Plains ${ }^{\circledR}$. Great Plains is designed to capture transactions and create financial reports. It utilizes lookup tables to find customer accounts and product codes, has built in validation rules, and can provide multiple- use reports. Based on their development of a small database, students can now appreciate the built-in controls of these forms that enter data into multiple tables, as well as the extensive array of pre-designed reports.

The IDEA software teaches them how to import data from other systems in order to have it read and manipulated by the auditing package. Students develop an audit plan that includes accounts receivable and accounts payables audit and fraud investigation, and a review of the inventory accounts. The ease with which students can utilize these packages is due in part to their familiarity with databases in general from their earlier class projects. As a result of all these exercises, students attest to their confidence in and understanding of the use of databases as the foundation for business knowledge. 


\section{Conclusion}

This paper has examined the instructional methodology known as problem-based learning and applied its concepts to teaching information systems and database functionality to a non-IS audience. It has presented some examples of exercises that tie student learning to existing knowledge of business transactions. By using a simple database exercise to expand on variety of information systems issues, from privacy to customer relationship management, many managerial information technology topics can be covered within the span of a single course.

\section{References}

Albanses, M. \& Mitchell, S. (1993). Problem based learning: a review of the literature on its outcomes and implementations issues. Academic Medicine 68, 52-81.

Bradbard, D. (2001). The use of a database project in the undergraduate MIS course. Proceedings of the Southeast Decision Sciences Institute, 207-209.

Calderon, T., Cheh, J. \& Chatham, M. (2002). An Examination of the Current State of Accounting Information Systems Education. The Review of Business Information Systems, 6 (2), 29-41.

Duffy, T. \& Cunningham, D. (1996). Constructivism: Implications for the design and delivery of instruction. In Jonassen, D. (Ed.) Handbook of Research for Educational Communications and Technology. New York, NY: Simon \& Schuster Macmillan.

Hollander, A., Denna, E., \& Cherrington, J. (1996). Accounting, Information Technology, and Business Solutions. Chicago, IL: Richard D. Irwin.

Milne, M. (1999) The promise of problem-based learning Chartered Accountants Journal 78(2), 37-40.

Moscove, S., Simkin, M. \& Bagranoff, N. (1999). Core Concepts of Accounting Information Systems. New York, NY: John Wiley \& Sons, Inc.

Rosenbaum, H. (2001). If We Build It, They Will Learn: Teaching E-Commerce in a Virtual Economy. Proceedings of the Seventh Americas Conference on Information Systems. Boston, MA.

Wilson, B. and Cole, P. (1996). Cognitive teaching models In Jonassen, D. (Ed.) Handbook of Research for Educational Communications and Technology. New York, NY: Simon \& Schuster Macmillan.

\section{Biography}

Dr. Moody received an MBA and PhD in Management Information Systems from the University of South Florida. She received a BSBA degree in Statistics from University of Florida and became a Certified Public Accountant (CPA) in Florida. Dr. Moody joined The Citadel faculty in 1993, where she teaches graduate and undergraduate courses in Management Information Systems, as well as undergraduate courses in Accounting and Accounting Information Systems.

Prior to joining the faculty, Dr. Moody worked for Price Waterhouse CPAs, GTE Corp., Eastern Airlines, and Jack Eckerd Corp. Dr. Moody has published articles in numerous journals, including MIS Quarterly, Expert Systems with Applications, and JMIS. She is a frequent presenter at both national and regional conferences. Her research interests are in the areas of the behavioral aspects of systems development and the managerial aspects of IS personnel.

1. Current research projects include: Investigation of attributes of exceptional systems analysts

2. An evaluation of employer perceptions of the most effective means for providing proof of competencies to aid in the selection of new hires. 